\title{
Household hygiene advice for patients with Clostridium difficile: Summary of hospital practice in Ontario, Canada
}

\author{
Catherine D. Egan; ${ }^{1,4}$ Andria Jones-Bitton; ${ }^{2,3}$ Jan M. Sargeant; ${ }^{2,3}$ J. Scott Weese ${ }^{1}$ \\ ${ }^{1}$ Department of Pathobiology, University of Guelph, Guelph, ON, Canada \\ ${ }^{2}$ Department of Population Medicine, University of Guelph, Guelph, ON, Canada \\ ${ }^{3}$ Centre for Public Health and Zoonoses, University of Guelph, Guelph, ON, Canada \\ ${ }^{4}$ School of Health and Life Sciences, Environmental Public Health, Conestoga College, Kitchener, ON, Canada
}

\section{Corresponding author:}

Catherine Egan, Department of Pathobiology, University of Guelph, Guelph, ON, Canada

cegan01@uoguelph.ca

\begin{abstract}
Background: While Clostridium difficile infection is a significant concern in healthcare settings, there is increasing evidence that transmission does not solely occur in hospitals and long-term care homes. Hospital patients are regularly discharged home following or during treatment, and it is likely that many excrete spores into their household environment, posing risks of reinfection to themselves and transmission of spores to others. Hence, recommendations on household hygiene might be important for control of $C$. difficile. The objective of this study was to investigate the information provided by Ontario hospitals to patients who have laboratory-confirmed symptomatic $C$. difficile infection with respect to household hygiene advice once they are discharged from hospital.

Methods: This cross-sectional study was conducted between January and August 2018 and included an anonymous online survey, a website scan of Ontario hospitals, and a content analysis of information provided to patients on discharge. The survey was distributed to practicing infection control professionals in Ontario hospitals through the IPAC Canada listserv. One response per hospital corporation was accepted.

Results: Responses were obtained from 46/145 (32\%) Ontario hospital corporations. The majority (30/46; 65\%) of respondents indicated they personally believed the household environment was important or very important in the transmission of C. difficile. Almost half $(22 / 46 ; 48 \%)$ of respondents reported that their hospital had a policy to provide household hygiene advice to patients when discharged home. However, analysis of 31 hospital information sheets from the website scan identified that $27 / 31$ $(88 \%)$ contained a statement that suggested there is little risk of transmission in households, and only $2 / 31(6.5 \%)$ provided the specific dilution of bleach that is known to be sporicidal.

Conclusion: The household hygiene advice provided by Ontario hospitals downplayed the likelihood of transmission of $C$. difficile spores in household environments and described a level of hygiene that is likely inadequate to prevent transmission of C. difficile spores in the home. This may contribute to recurrent infection and colonization of household contacts.
\end{abstract}

\section{KEYWORDS}

Clostridium difficile; hygiene; household; home; environmental cleaning; decontamination

\section{INTRODUCTION}

Clostridium difficile infection (CDI) has been recognized as the leading cause of antimicrobial-associated diarrhea in healthcare settings for decades [1]. Transmission also occurs in community settings through the same mechanisms as healthcare settings, namely directly via patients with symptomatic CDI [2], asymptomatic carriers [3-5], and indirectly by contaminated environmental surfaces [6]. It is estimated that communityassociated CDI represents approximately $30 \%$ of overall CDI cases in the United States [7] and Canada [8], and communitybased transmission of $C$. difficile from people with $\mathrm{CDI}$ to their household contacts has been identified [9].

Of particular concern with CDI is recurrent disease, with recurrence in $25 \%$ to $87.5 \%$ of cases following treatment [10].
Recurrence of clinical disease is thought to be a result of relapse or reinfection [11]. It is challenging to distinguish between these two courses, as it is difficult to identify the specific acquisition of the organism and the mechanism of recurrence (persistent C. difficile in the intestine or ingestion of spores from the environment) [12].

People with CDI may excrete spores for at least five weeks following treatment $[13,14]$. Spores can persist in the environment for several months [15], if not years [16], and are difficult to destroy, as they are resistant to many interventions, including several disinfectants [10]. Environmental cleaning practice in hospitals includes consideration of the type of disinfectant, contact time required, compatibility of cleaning

Acknowledgements: The authors would like to acknowledge and thank IPAC Canada for distributing the survey.

Conflicts of interest: None.

Funding: None. 
equipment (wipes/cloths) with disinfectants, training for staff, as well as monitoring for efficacy [17]. These aspects are generally not considered in household cleaning routines [18].

On average, CDI increases a patient's length of stay in hospital by seven days [19] and since shedding of spores can persist for weeks after clinical resolution, it is likely that many patients with $\mathrm{CDI}$ are discharged from hospital before the infectious period has lapsed. Testing of patients at the time of discharge for $C$. difficile shedding is not routinely performed and is not recommended [20]. C. difficile spores have been found in households of those with recurrent CDI, with one study finding C. difficile-positive samples in nine out of ten households [12]. Patients with CDI may have contamination of their skin (groin, chest, abdomen, forearms, hands) [21] and their household environment [22-24], even if they were asymptomatic [25] or did not meet the clinical criteria to be tested for CDI [26]. A positive correlation has also been demonstrated between the presence of $C$. difficile on healthcare workers' hands and the level of spore contamination of the hospital environment $[27,28]$. C. difficile spores also may be present in households without a person with $\mathrm{CDI}$, as the spores have been isolated from retail food, animals, soil, and water [29]. Thus, it is likely that $C$. difficile spores are an important source of reinfection (recurrence) or transmission through high-touch surfaces in households [9, 30, 31].

Current infection prevention and control advice for the home is based on the assumption that transmission of infection or colonization is rarely investigated in households of CDI patients [32]. Infection with C. difficile occurs after two events: exposure to $C$. difficile spores and disruption of the gastrointestinal (Gl) microbiota [33]. Disruption of the Gl tract does not always occur at the time of exposure to the C. difficile spores and symptoms would not start until disruption occurs [34]. This makes it difficult to connect CDI in household contacts to exposure to an index case or contaminated environmental surfaces since the onset of symptoms occurs at a later time.

$\mathrm{CDI}$ is not a disease of public health significance in Ontario (as per Ontario Regulation 135/18 - Designation of Diseases), meaning that it is not reported to public health and individual cases are not tracked. Mandated reporting of CDI rates occurs as part of provincial patient safety indicator reporting for hospitals, and only outbreaks in public hospitals are classified as diseases of public health significance. Hospital outbreaks are declared based on exceedance of thresholds of nosocomial cases in a defined period based on the number of beds in the unit.

Specialized practices are required for decontamination of the environment to remove and kill C. difficile spores. Using a sporicidal agent such as bleach at an appropriate concentration and contact time (1,000 to 5,000 ppm for ten to 30 minutes, depending on concentration) is necessary to control C. difficile [20].

The objective of this study was to investigate the information provided by Ontario hospitals to patients with laboratory-confirmed symptomatic $C$. difficile infection with respect to household hygiene advice once they are discharged from hospital.

\section{METHODS}

This cross-sectional study was conducted between January and August 2018 and included an anonymous online questionnaire, a website scan, and a content analysis of patient information documents. The online questionnaire was approved by the Research Ethics Board at the University of Guelph (REB\# 17-11-005) and was pre-tested by three infection control professionals (ICPs). The questionnaire was distributed through the IPAC Canada listserv in order to target ICPs working at all hospitals in Ontario. The online questionnaire was open from March 29, 2018 to May 1, 2018, and weekly reminders were sent through the listserv.

The questionnaire used closed-ended questions (rating scales, multiple choice, yes/no questions) to confirm the employment position and professional experience of the respondent and to gather data on hospital size, infection prevention and control resources at each hospital, hospital practice for providing patient information on household hygiene for patients with $\mathrm{CDI}$, barriers to providing information on household hygiene, and hospital experience with CDI (monthly rates of CDI and outbreaks in 2017). Respondents were invited to submit copies of patient information sheets. Nine hospitals voluntarily shared patient information sheets with their survey results.

A scan of Ontario hospital websites was conducted between January and August 2018 with the intent of identifying household hygiene advice for patients with C. difficile. A list of Ontario hospitals was compiled from Local Health Integration Network (LHIN) websites. The website of each hospital was searched by the primary author for "C. difficile" or "Clostridium difficile" through the website search function. If no results were found, the same search terms were used to search the Patient Safety area of the website.

Content analysis as per Erlingsson \& Brysiewicz (2017) [35] was conducted on the patient information sheets and Web pages by comparing and sorting text into the categories of the patient information sheets provided by the Ontario Ministry of Health and Long-Term Care (MOHLTC) [36] and Public Health Ontario's Provincial Infectious Diseases Advisory Committee (PIDAC) [20]. These categories were: general statement of risk of transmission in the home, hand hygiene, cleaning practice, and cleaning fabric (laundry). The goal of this analysis was to determine how many patient information sheets were aligned with MOHLTC and PIDAC guidelines and, if deviations from these guidelines occurred, what they were.

\section{RESULTS}

78 responses to the questionnaire were attempted, 26 of which did not contain responses to any of the questions and were therefore deleted. Six responses were identified as duplicates in that there were responses from that same hospital corporation. Duplicates were managed by including only the most complete response. 46 responses remained, representing $32 \%$ of 145 Ontario hospital corporations. Responses were received from hospitals in each of the LHIN 
areas in Ontario except for the North West area. Once the survey closed, all hospital names were deleted from the data to maintain confidentiality. Information about respondents, their experience and certification, and about hospitals and their experience with CDI is contained in Table 1.

\begin{tabular}{|c|c|}
\hline Individual Respondent Characteristics & $\begin{array}{c}\text { Count (\%) } \\
N=46\end{array}$ \\
\hline $\begin{array}{l}\text { ICP } \\
\text { Manager }\end{array}$ & $\begin{array}{c}44(96) \\
2(4)\end{array}$ \\
\hline
\end{tabular}

\begin{tabular}{|l|c|}
\hline Years as an ICP & \\
Less than one year & $2(4)$ \\
One to five years & $14(31)$ \\
Six to ten years & $10(22)$ \\
More than ten years & $10(22)$ \\
Managers not ICPs (not applicable) & $2(4)$ \\
\hline
\end{tabular}

\begin{tabular}{|l|l|}
\hline $\begin{array}{l}\text { Certificate of Infection Control and } \\
\text { Epidemiology }\left(\mathbf{C I C}^{\circledR}\right)\end{array}$ & \\
Yes & $33(72)$ \\
No & $13(28)$ \\
\hline
\end{tabular}

\begin{tabular}{|l|l|}
\hline Hospital Characteristics & Count (\%) \\
\hline Number of physical sites in hospital & \\
corporation* & \\
One site & $20(44)$ \\
Two sites & $12(26)$ \\
More than two sites & $14(30)$ \\
\hline
\end{tabular}

\begin{tabular}{|l|c|}
\hline $\begin{array}{l}\text { Self-reported CDI rate** compared to } \\
\text { provincial average }\end{array}$ & \\
Always above & $6(13)$ \\
Sometimes above & $9(20)$ \\
Sometimes below & $4(9)$ \\
Always below & $21(45)$ \\
No answer & $6(13)$ \\
\hline
\end{tabular}

\begin{tabular}{l|c}
\hline CDI outbreak declaration & \\
No outbreak declared in 2017 & $42(92)$ \\
CDI outbreak declared in 2017 & $2(4)$ \\
No answer & $2(4)$ \\
\hline
\end{tabular}

\begin{tabular}{|l|c|}
\hline Ratio of ICPs to number of hospital beds $* * *$ & \\
$<0.01$ ICP to bed & $24(52)$ \\
$>0.01$ ICP to bed & $20(44)$ \\
No answer & $2(4)$ \\
\hline
\end{tabular}

ICP, infection control professional; CDI Clostridium difficile infection

* "Hospital corporation" is used to denote multiple hospital sites operating under one administrative structure.

${ }^{* *}$ Ontario patient safety indicator: Number of $C$. difficile cases divided by the number of total patient days $x 1,000$. Note that these rates were not validated against reported rates.

$* * *$ Ratio of ICPs to hospital beds calculated and categorized according to the recommended one ICP per 100 hospital beds [37].
Household hygiene information for patients with CDI Almost half $(22 / 46 ; 48 \%)$ of hospitals indicated that they had a policy to provide household hygiene advice to CDI patients when discharged home. ICPs were the position most commonly responsible $(9 / 22 ; 40 \%)$ for providing information to patients on discharge (Table 2). All hospitals with policies indicated that they had written information for patients and 12/22 (55\%) indicated they also had verbal conversations with patients about household hygiene. Despite having policies to do so, only 5/22 (23\%) indicated that they always provide information (Table 2). The most common barriers cited to providing advice to patients were lack of staff time and a lack of knowledge about what information to provide (Table 2). Slightly more than half $(24 / 46 ; 52 \%)$ of the hospitals reported that patients sometimes asked questions about household management for $C$. difficile; three of 46 hospitals (7\%) indicated questions occur "often."

\section{TABLE 2: Implementation of household hygiene}

information for patients with CDI provided by hospitals with policies.

\begin{tabular}{|l|c|}
\hline Implementation Components & $\begin{array}{c}\text { Count (\%) } \\
\mathbf{N}=\mathbf{2 2}\end{array}$ \\
\hline $\begin{array}{l}\text { Source(s) used to develop patient information } \\
\text { (respondents could select all that apply): }\end{array}$ & \\
Provincial advisory/committee & $19(86)$ \\
Local public health unit & $19(86)$ \\
Provincial government & $8(36)$ \\
Federal government & $3(14)$ \\
Peer organization & $2(9)$
\end{tabular}

\section{Most responsible person to provide} information to patient:

ICP

Nurse

No specific position is responsible

Other

$5(22)$

Physician

\section{Frequency with which information is} provided to patients on discharge:

Always

Most of the time

About half of the time

Sometimes

Do not know

Barriers to providing household hygiene advice on discharge (respondents could select all that apply):

Not enough staff time to talk to each patient Lack of knowledge about what information to provide

Lack of interest from patients to receive information

Lack of information about when CDI patients are discharged

Do not know

No barriers encountered

ICP: Infection control professional

CDI: Clostridium difficile infection 
In addition to the 22 hospitals that indicated they have policies to provide information to patients with CDI who are being discharged home, ten of the 24 (42\%) hospitals without policies indicated that information was provided, suggesting that the majority $(32 / 46 ; 70 \%)$ of hospitals intend to provide some information to patients regardless of the existence of a formal policy.

Several reasons were selected for hospitals not having policies to provide household hygiene advice: hospitals are not responsible for activities that occur outside the hospital (2/24; $8 \%$, CDI is an uncommon occurrence $(1 / 24 ; 4 \%)$, patients are not interested $(1 / 24 ; 4 \%)$, and uncertain as to what information to provide
$(1 / 24 ; 4 \%)$. Ten (42\%) stated that although they do not have a policy, they do have information that may be provided; eight (33\%) did not know why they do not have a policy, and one (4\%) did not answer. No respondent indicated that it was because they did not think household hygiene was a concern.

Hospital information sheets on household hygiene for patients A total of 31 patient information sheets from 31 separate hospital corporations were identified and used for analysis. Nine respondents to the online questionnaire voluntarily submitted copies of their information sheets, while 22 additional patient information sheets were identified through the searches of

\section{TABLE 3: Comparisons of hospital patient information sheets by PIDAC and MOHLTC categories.}

\begin{tabular}{l} 
Category \\
\hline General \\
statement of risk \\
of transmission \\
in the household
\end{tabular}

$$
N=31
$$

PIDAC - "Generally speaking, people in the hospital are sicker and get more infections than people in the community. Once home, precautions are not as strict. Nonetheless, certain steps can help reduce the risk of spreading this germ to family members and other visitors."

MOHLTC - "Healthy people like your family and friends who are not taking antibiotics are at very low risk of getting C. diff disease."

"Healthy people like your family and friends who are not taking antibiotics are at very low $\quad 20$ (65\%) risk of getting C. diff disease."

"Generally speaking, people in the hospital are sicker and get more infections than people $3(10 \%)$ in the community. Once home, precautions are not as strict. Nonetheless, certain steps can help reduce the risk of spreading this germ to family members and other visitors."

\begin{tabular}{|l|l}
\hline "The chance of spreading the illness to healthy people is small." & $1(3 \%)$
\end{tabular}

"The risk is low that a healthy person will get C. difficile."

$1(3 \%)$

"There is a slight chance of spreading $C$. difficile to a family member, especially

$1(3 \%)$ if one is sick."

"Once you are back home, you can return to your normal routine. Often, the diarrhea

$1(3 \%)$ will be better or completely gone before you go home. This makes giving C. diff to other people much less likely."

No answer.

$4(13 \%)$

Hand hygiene

PIDAC - "Wash hands for at least 15 seconds after using the toilet, before eating or before preparing food. Caregivers should wash their hands after providing care."

MOHLTC - "Wash your hands for at least 15 seconds: after using the toilet, after touching dirty surfaces, before eating, before preparing meals."

"Wash your hands for at least 15 seconds after using the toilet, before eating or before $\quad 25(80 \%)$ preparing food."

"Practice good hand hygiene."

$2(7 \%)$

"Hand washing is the most important thing that you can do, especially after you use the washroom and before you eat."

"Everyone who might help you with personal care should wash his or her hands after contact with you."

No answer.

$2(7 \%)$

$1(3 \%)$

\begin{tabular}{|c|c|c|}
\hline & $1(3 \%)$
\end{tabular}

Cleaning agents $\quad$ PIDAC - "This germ can be destroyed by most household cleaning products or diluted household bleach."

MOHLTC - "...all-purpose household cleaner."

"Use either a household cleaner diluted according to the instructions or diluted household bleach."

"Use an all-purpose cleaner."

$10(33 \%)$

"Diluted household bleach can kill this germ."


TABLE 3: continued

\begin{tabular}{l|l} 
Category & Statement Frequency (\%)
\end{tabular}

$\mathbf{N}=\mathbf{3 1}$

How to clean $\quad$ PIDAC - "No special precautions are required to clean your home. Wet a clean cloth thoroughly with a properly diluted cleaning product or use a pre-packaged disinfectant wipe. Wipe surfaces starting from the cleanest area and moving towards the dirtiest area, paying special attention to areas such as the toilet and bathroom sink. Let the surfaces air dry. This will allow enough contact time with the cleaning product to kill the bacteria."

MOHLTC - "Follow directions on label and wet surface well and clean using good friction, allow surface to air dry, pay special attention to areas that may be soiled with feces such as the toilet and sink. Remove any visible feces and then clean as described above."

"Wet surface well and clean using good friction; allow surface to air dry; pay special $11(35 \%)$ attention to areas that may be soiled with stool such as the toilet and sink. If you see stool remove first and then clean as described above."

"No special precautions are required to clean your home. Wet a clean cloth thoroughly with a properly diluted cleaning product or use a pre-packaged disinfectant wipe. Wipe surfaces starting from the cleanest area and moving towards the dirtiest area, paying special attention to areas such as the toilet and bathroom sink. Let surfaces air dry. This will allow enough contact time with the cleaning product to kill the bacteria."

\begin{tabular}{|l|l} 
"Frequent, thorough cleaning of the washroom is recommended." & $3(10 \%)$
\end{tabular}

"If you have 2 washrooms in your home, try not to share the toilet with another person until the $C$. difficile infection is gone. We know that this may not always be possible. If you must share the toilet with others, wipe down the toilet seat with a disinfectant (such as Lysol) after each use. Clean your toilet, commode or bedpan with a disinfectant at least once a day."

"Be sure to follow the instructions on the label and use good friction (rubbing) when cleaning a surface. Toilets and bathrooms need extra attention. If feces have splashed onto a surface, they must be removed first, and then cleaning done with the household cleaner. If it is possible, use your own bathroom until your diarrhea stops."

"Wet the surface and scrub with a damp cloth. Rubbing hard is the only way to get rid of spores; allow the surface to dry; take special care with areas that maybe soiled by stool (toilets, sinks and taps); wipe away any stool you see, then clean as above. Do not use the cleaning cloth for anything else - wash it in hot, soapy water, or if you use paper towels you can throw them away."

"Keep a regular cleaning schedule. The most important rooms to keep clean are the bathroom and the kitchen. If you are not able to do any cleaning, you will need to inform the people who plan your care when you return home. Wet the surface well and clean using good friction; allow the surface to air dry; pay special attention to areas that may be soiled with stool such as the toilet and sink; remove any stool and then clean as described above."

No answer.

Fabrics/laundry $\quad$ PIDAC - No statement.

MOHLTC - "Wash clothes/fabric separately if they are heavily soiled with feces: rinse off feces, clean in a hot water cycle with soap, dry in dryer on high heat, dry clean where appropriate."

"Wash clothes/fabric separately if they are heavily soiled with stool: rinse stool off, clean in a hot water cycle with soap; dry items in the dryer if possible."

"Clothes and fabrics can be laundered as usual. A hot water wash with soap and hot dry are often recommended. [If] items are heavily soiled with feces, the feces should be rinsed off prior to washing."

"Wash clothes with household laundry detergent on a regular cycle; if your clothes are heavily soiled with body fluids, like poop or urine, pre-soak and then wash them separately with detergent."

No answer. 
Ontario hospital websites. Table 3 contains guidelines from PIDAC and MOHLTC and the frequency with which they or alternate text appear in hospital information sheets organized by category.

Only 12/31 (39\%) patient information sheets suggested a chemical agent that contained bleach, and only 2/31 (6.5\%) provided the specific dilution of one part household bleach to ten parts water (approximately 5,000 ppm), which is sporicidal [20].

\section{DISCUSSION}

There is a large body of evidence that patients with CDI contaminate their hospital rooms with spores that survive for extended periods [38, 39], that contaminated environmental surfaces can be a reservoir for C. difficile in hospitals [38], and that environmental cleaning can disrupt transmission. The same risks exist in the household environment for patients recovering from $\mathrm{CDI}$ at home [40].

While the majority $(30 / 46 ; 65 \%)$ of respondents to our questionnaire indicated that they personally believe the household environment is important or very important in the transmission of C. difficile, none of the patient information provided by hospitals clearly articulated the potential for a $\mathrm{CDI}$ patient to be excreting spores in their stool for several weeks and that the spores could survive for months in the environment, thus creating a possible reservoir in the home.

The responses to the online questionnaire indicated that questions from patients about household hygiene are infrequent. Patients may not ask questions about the type of household hygiene they should be practicing because they do not know they should be concerned about a risk of transmission in their home, or their questions may not be relayed to the ICPs in the hospital who were the respondents of the questionnaire.

\section{General statement of risk}

The patient information sheets contained statements indicating that patients with C. difficile do not pose a significant risk to household members. While it may be true that the risk of acquiring $\mathrm{CDI}$ is low, the risk of ingesting spores by household contacts and the CDI patient exists. It is reasonable to assume that patients with CDI are frequently discharged into households with other high-risk individuals, particularly elderly individuals, increasing the risk. A targeted hygiene process [18] that considers the pathogen (what agent would be effective to kill it, how long to continue the process, etc.) and the health status of the people (healthy or immunocompromised) in the household (including caregivers) should be used to determine the hygiene practices required [41]. In this context, hygiene refers to both decontamination of the environment and personal hygiene (toileting, hand hygiene, etc.) of the individuals living in the household.

\section{Hand hygiene}

Information on hand hygiene was provided by 30/31 (97\%) hospitals. Most hospitals $(25 / 31 ; 81 \%)$ indicated when hands should be washed and for how long; however, they did not specify that handwashing should be done with soap and water. Neither PIDAC nor MOHLTC provided specifics on the type of product to be used for hand hygiene.

\section{Cleaning agent}

Many $(11 / 31 ; 35 \%)$ of the information sheets stated that an "all-purpose household cleaner" is sufficient for household cleaning when a patient with CDI is in the home. This is likely not accurate, given that "cleaners" are not necessarily bactericidal, and even bactericidal disinfectants may not be effective against hardy clostridial spores [42]. Sporicidal agents (along with physical removal) are necessary to eliminate C. difficile spores from the environment [43].

\section{How to clean}

Many patient information sheets made statements about cleaning using "thorough" and "regularly" to describe frequency or processes (i.e., "regular cleaning schedule" or "frequent thorough cleaning"). "Thorough" and "regular" were not defined and there was no explanation as to why thorough cleaning was necessary, given that it was stated that there was no risk to family members.

The general public tends to understand "clean" to mean "an absence of dirt," but solely removing visible dirt is an insufficient process to remove C. difficile spores [18]. Cleaning cloths and wipes must be handled and used carefully to avoid cross-contamination of surfaces [44], but specific information on how to handle cleaning equipment was lacking from the patient information sheets. Contact times for some agents are quite long (several minutes) and vary depending on the concentration of the active ingredient [45]; many of the information sheets may therefore be inaccurate, as they state that contact time will be sufficient without considering the specific cleaning product.

\section{Fabrics/laundry}

Advice on managing fecally contaminated fabrics (laundry) was fairly consistent in the documents for patients. However, there was no advice for how to manage soft furnishings such as mattresses despite the fact that they have been shown to be a source of contamination in healthcare settings [46]. Appropriate management of mattress and furniture covers or application of an appropriate agent to furniture and mattresses could reduce the microbial load, which can minimize exposure to spores [47, 48].

\section{Limitations of this study}

The response rate to the online questionnaire was low (32\% of Ontario hospital corporations) and responses were not obtained from all areas of the province, indicating that the results may not be fully representative of all hospitals in Ontario. The analysis also did not consider the verbal conversations that were reported to have taken place between ICPs and patients, which may have contained additional information. Additionally, a variety of healthcare personnel have contact with patients and the range of advice that is given by different personnel in each facility was not identifiable. 


\section{CONCLUSION}

The majority of Ontario hospitals surveyed (67\%) provided advice to patients with CDI when discharged home. However, the advice downplayed the likelihood of transmission of $C$. difficile spores in household environments and described a basic level of hygiene that may be inadequate to prevent the transmission of $C$. difficile spores in the home environment. This may result in colonization of household members or recurrence in CDI patients as well as the creation of a reservoir in the household environment. There is an opportunity to reduce the risk of transmission in the home by being more prescriptive with the household hygiene advice provided to patients, including clearly outlining the risk of transmission in households, an appropriate decontamination process, and the use of a sporicidal agent. It is also recommended that standardized patient information be developed and used at all hospitals across Ontario.

\section{REFERENCES}

1. McDonald, L. C., Gerding, D. N., Johnson, S., Bakken, J. S., Carroll, K. C., Coffin, S. E., Dubberke, E. R., Garey, K. W., Gould, C. V., Kelly, C., Loo, V., Shaklee Sammons, J., Sandora, T. J., \& Wilcox, M. H. (2018). Clinical practice guidelines for Clostridium difficile infection in adults and children: 2017 update by the Infectious Diseases Society of America (IDSA) and Society for Healthcare Epidemiology of America (SHEA). Clinical Infectious Diseases, 66(7), e1-e48. doi: https://doi.org/10.1093/cid/cix1085

2. Donskey, C. J. (2010). Preventing transmission of Clostridium difficile: Is the answer blowing in the wind? Clinical Infectious Diseases, 50(11), 1458-1461. doi: https://doi.org/10.1086/652649

3. Longtin, Y., Paquet-Bolduc, B., Gilca, R., Garenc, C., Fortin, E., Longtin, J., Trottier, S., Gervais, P., Roussy, J. F., Levesque, S., BenDavid, D., Cloutier, I., \& Loo, V. G. (2016). Effect of detecting and isolating Clostridium difficile carriers at hospital admission on the incidence of $C$ difficile infections: A quasi-experimental controlled study. JAMA Internal Medicine, 176(6), 796-804. doi: 10.1001/ jamainternmed.2016.0177

4. Blixt, T., Gradel, K. O., Homann, C., Seidelin, J. B., Schonning, K., Lester, A., Houlind, J., Stangerup, M., Gottlieb, M., \& Knudsen, J. D. (2017). Asymptomatic carriers contribute to nosocomial Clostridium difficile infection: A cohort study of 4508 patients. Gastroenterology, 152(5), 1031-1041.e2. doi: https://doi.org/10.1053/j. gastro.2016.12.035

5. Riggs, M. M., Sethi, A. K., Zabarsky, T. F., Eckstein, E. C., Jump, R. L. P., \& Donskey, C. J. (2007). Asymptomatic carriers are a potential source for transmission of epidemic and nonepidemic Clostridium difficile strains among long-term care facility residents. Clinical Infectious Diseases, 45(8), 992-998. doi: https://doi. org/10.1086/521854

6. Alam, M. J., Anu, A., Walk, S. T., \& Garey, K. W. (2014). Investigation of potentially pathogenic Clostridium difficile contamination in household environs. Anaerobe, 27, 31-33. doi: https://doi. org/10.1016/j.anaerobe.2014.03.002

7. Lessa, F. C. (2013). Community-associated Clostridium difficile infection: How real is it? Anaerobe, 24, 121-123. doi: https://doi. org/10.1016/j.anaerobe.2013.01.006

8. Canadian Nosocomial Infection Surveillance Program (CNISP). (2017). Summary report of healthcare associated infection (HAI), antimicrobial resistance (AMR) and antimicrobial use (AMU) surveillance data from January 1, 2013 to December 31, 2017. Retrieved from https://ipac-canada.org/photos/custom/Members/CNISPpublications/CNISP\%202013-2017\%20Report_Final_EN.pdf
9. Loo, V. G., Brassard, P., \& Miller, M. A. (2016). Household transmission of Clostridium difficile to family members and domestic pets. Infection Control \& Hospital Epidemiology, 37(11), 13421348. doi: https://doi.org/10.1017/ice.2016.178

10. Oka, K., Osaki, T., Hanawa, T., Kurata, S., Okazaki, M., Manzoku, T., Takahashi, M., Tanaka, M., Taguchi, H., Watanabe, T., Inamatsu, T., \& Kamiya, S. (2012). Molecular and microbiological characterization of Clostridium difficile isolates from single, relapse, and reinfection cases. Journal of Clinical Microbiology, 50(3), 915-921. doi: 10.1128/JCM.05588-11

11. Figueroa, I., Johnson, S., Sambol, S. P., Goldstein, E. J. C., Citron, D. M., \& Gerding, D. N. (2012). Relapse versus reinfection: Recurrent Clostridium difficile infection following treatment with fidaxomicin or vancomycin. Clinical Infectious Diseases, 55(Suppl 2), S104-S109. doi: 10.1093/cid/cis357.

12. Shaughnessy, M. K., Bobr, A., Kuskowski, M. A., Johnston, B. D., Sadowsky, M. J., Khoruts, A., \& Johnson, J. R. (2016). Environmental contamination in households of patients with recurrent Clostridium difficile infection. Applied and Environmental Microbiology, 82(9), 2686-2692. doi: 10.1128/ AEM.03888-15

13. Sethi, A. K., Al-Nassir, W. N., Nerandzic, M. M., Bobulsky, G. S., Donskey, C. J., \& Al-Nassir, W. N. (2010). Persistence of skin contamination and environmental shedding of Clostridium difficile during and after treatment of $C$. difficile infection. Infection Control \& Hospital Epidemiology, 31(1), 21-27. doi: 10.1086/649016

14. Jinno, S., Kundrapu, S., Guerrero, D. M., Jury, L. A., Nerandzic, M. M., \& Donskey, C. J. (2012). Potential for transmission of Clostridium difficile by asymptomatic acute care patients and long-term care facility residents with prior $C$. difficile infection. Infection Control \& Hospital Epidemiology, 33(6), 638-639. doi: 10.1086/665712

15. Kim, K. H., Fekety, R., Batts, D. H., Brown, D., Cudmore, M., Silva, Jr., J., \& Waters, D. (1981). Isolation of Clostridium difficile from the environment and contacts of patients with antibioticassociated colitis. Journal of Infectious Diseases, 143(1), 42-50.

16. Rupnik, M., Wilcox, M. H., \& Gerding, D. N. (2009). Clostridium difficile infection: New developments in epidemiology and pathogenesis. Nature Reviews Microbiology, 7(7), 526-536. doi: 10.1038/nrmicro2164

17. Otter, J. A., Yezli, S., Salkeld, J. A., \& French, G. L. (2013). Evidence that contaminated surfaces contribute to the transmission of hospital pathogens and an overview of strategies to address contaminated surfaces in hospital settings. American Journal of Infection Control, 41(Suppl 5), S6-S11. doi: 10.1016/j. ajic.2012.12.004

18. Bloomfield, S. F., Carling, P. C., \& Exner, M. (2017). A unified framework for developing effective hygiene procedures for hands, environmental surfaces and laundry in healthcare, domestic, food handling and other settings. GMS Hygiene and Infection Control, 12, Doc08. doi: 10.3205/dgkh000293

19. Gabriel, L., \& Beriot-Mathiot, A. (2014). Hospitalization stay and costs attributable to Clostridium difficile infection: A critical review. Journal of Hospital Infection, 88(1), 12-21. doi: 10.1016/j. jhin.2014.04.011

20. Ontario Agency for Health Protection and Promotion, Provincial Infectious Diseases Advisory Committee (PIDAC). (2013). Annex C: Testing, surveillance and management of Clostridium difficile in all health care settings. Retrieved from https:/www.publichealthontario.ca/-/media/documents/cdiff-testing-surveillance-management.pdf?la $=$ en

21. Bobulsky, G. S., Al-Nassir, W. N., Riggs, M. M., Sethi, A. K., \& Donskey, C. J. (2008). Clostridium difficile skin contamination 
in patients with $C$. difficile-associated disease. Clinical Infectious Diseases, 46(3), 447-450. doi: 10.1086/525267

22. Biswas, J. S., Patel, A., Otter, J. A., van Kleef, E., \& Goldenberg, S. D. (2015). Contamination of the hospital environment from potential Clostridium difficile excretors without active infection. Infection Control \& Hospital Epidemiology, 36(8), 975-977. doi: https://doi.org/10.1017/ice.2015.79

23. Warrack, S., Duster, M., Van Hoof, S., Schmitz, M., \& Safdar, N. (2016). Clostridium difficile in a children's hospital: Assessment of environmental contamination. American Journal of Infection Control, 42(7), 802-804. doi: 10.1016/j.ajic.2014.03.008

24. Blakney, R., Gudnadottir, U., Warrack, S., O'Horo, J. C., Anderson, M., Sethi, A., Schmitz, M., Wang, J., Duster, M., Ide, E., \& Safdar, N. (2015). The relationship between patient functional status and environmental contamination by Clostridium difficile: A pilot study. Infection, 43(4), 483-487. doi: 10.1007/s15010015-0770-1

25. Hung, Y.-P., Lee, J.-C., Lin, H.-J., Liu, H.-C., Wu, Y.-H., Tsai, P.-J., \& Ko, W.-C. (2015). Clinical impact of Clostridium difficile colonization. Journal of Microbiology, Immunology and Infection, 48(3), 241-248. doi: 10.1016/j.jmii.2014.04.011

26. Kundrapu, S., Sunkesula, V., Tomas, M., \& Donskey, C. J. (2015). Skin and environmental contamination in patients diagnosed with Clostridium difficile infection but not meeting clinical criteria for testing. Infection Control \& Hospital Epidemiology, 36(11), 13481350. doi: 10.1017/ice.2015.191

27. Davies, A., Pottage, T., Bennett, A., \& Walker, J. (2011). Gaseous and air decontamination technologies for Clostridium difficile in the healthcare environment. Journal of Hospital Infection, 77(3), 199-203. doi: 10.1016/j.jhin.2010.08.012

28. Samore, M. H., Venkataraman, L., DeGirolami, P. C., Arbeit, R. D., \& Karchmer, A. W. (1996). Clinical and molecular epidemiology of sporadic and clustered cases of nosocomial Clostridium difficile diarrhea. American Journal of Medicine, 100(1), 32-40.

29. Gould, L. H., \& Limbago, B. (2010). Clostridium difficile in food and domestic animals: A new foodborne pathogen? Clinical Infectious Diseases, 51(5), 577-582. doi: 10.1086/655692

30. Scott, E. (2013). Community-based infections and the potential role of common touch surfaces as vectors for the transmission of infectious agents in home and community settings. American Journal of Infection Control, 41(11), 1087-1092. doi: 10.1016/j. ajic.2013.05.014

31. Shaffer, M., \& Lozupone, C. (2018). Prevalence and source of fecal and oral bacteria on infant, child, and adult hands. mSystems, 3(1), e00192-17. doi: 10.1128/mSystems.00192-17

32. Pépin, J., Gonzales, M., \& Valiquette, L. (2012). Risk of secondary cases of Clostridium difficile infection among household contacts of index cases. Journal of Infection, 64(4), 387-390. doi: 10.1016/j.jinf.2011.12.011

33. Tracey, L., Kirke, A., Armstrong, P., \& Riley, T. V. (2015). From the hospital to the home - The rise and rise of Clostridium difficile infection. Australian Family Physician, 44(10), 712-717.

34. Durovic, A., Widmer, A. F., \& Tschudin-Sutter, S. (2018). New insights into transmission of Clostridium difficile infection-narrative review. Clinical Microbiology \& Infection, 24(5), 483-492. doi: 10.1016/j.cmi.2018.01.027

35. Erlingsson, C., \& Brysiewicz, P. (2017). A hands-on guide to doing content analysis. African Journal of Emergency Medicine, 7(3), 93-99. doi: 10.1016/j.afjem.2017.08.001

36. Ministry of Health and Long-Term Care (MOHLTC). (2006). Clostridium difficile - Fact sheet. Retrieved from http://www. hqontario.ca/portals/0/Documents/pr/ps-fact-sheet-c-diff-en.pdf

37. Ontario Agency for Health Protection and Promotion, Provincial Infectious Diseases Advisory Committee (PIDAC). (2012). Best practices for infection prevention and control programs in Ontario in all health care settings (3rd Ed.). Retrieved from https://www. publichealthontario.ca/-/media/documents/bp-ipac-hc-settings. pdf? la $=$ en

38. Weber, D. J., Anderson, D. J., Sexton, D. J., \& Rutala, W. A. (2013). Role of the environment in the transmission of Clostridium difficile in health care facilities. American Journal of Infection Control, 41(Suppl 5), S105-S110. doi: 10.1016/j. ajic.2012.12.009

39. Dubberke, E. R., Reske, K. A., Noble-Wang, J., Thompson, A., Killgore, G., Mayfield, J., Camins, B., Woeltje, K., McDonald, J. R., McDonald, L. C., \& Fraser, V. J. (2007). Prevalence of Clostridium difficile environmental contamination and strain variability in multiple health care facilities. American Journal of Infection Control, 35(5), 315-318. doi: 10.1016/j.ajic.2006.12.006

40. Girotra, M., Abraham, R. R., \& Pahwa, M. (2013). Clostridium difficile infection: How safe are the household contacts? American Journal of Infection Control, 41(11), 1140-1141. doi: 10.1016/j. ajic.2013.06.011

41. Aiello, A. E., Larson, E. L., \& Sedlak, R. (2008). Personal health: Bringing good hygiene home. American Journal of Infection Control, 36(Suppl 10), S152-S165. doi: 10.1016/j.ajic.2008.09.009

42. Ontario Agency for Health Protection and Promotion, Provincial Infectious Diseases Advisory Committee (PIDAC). (2012). Best practices for environmental cleaning for prevention and control of infections in all health care settings (2nd Ed.). Retrieved from http://www.ontla.on.ca/library/repository/mon/26011/318661.pdf

43. Rutala, W. A., Gergen, M. F., \& Weber, D. J. (2012). Efficacy of different cleaning and disinfection methods against Clostridium difficile spores: Importance of physical removal versus sporicidal inactivation. Infection Control \& Hospital Epidemiology, 33(12), 1255-1258. doi: 10.1086/668434

44. Cadnum, J. L., Hurless, K. N., Kundrapu, S., \& Donskey, C. J. (2013). Transfer of Clostridium difficile spores by nonsporicidal wipes and improperly used hypochlorite wipes: Practice + product $=$ perfection. Infection Control \& Hospital Epidemiology, 34(4), 441-442. doi: 10.1086/669871

45. Canadian Agency for Drugs and Technologies in Health (CADTH). (2014). Non-manual technique for room disinfection in healthcare facilities: A review of clinical effectiveness and guidelines. Retrieved from https://www.cadth.ca/sites/default/files/pdf/ htis/nov-2014/RC0545\%20Room\%20Disinfection\%20Final.pdf

46. Creamer, E., \& Humphreys, H. (2008). The contribution of beds to healthcare-associated infection: The importance of adequate decontamination. Journal of Hospital Infection, 69(1), 8-23. doi: 10.1016/j.jhin.2008.01.014

47. Sexton, J. D., Wilson, A. M., Sassi, H. P., \& Reynolds, K. A. (2018) Tracking and controlling soft surface contamination in health care settings. American Journal of Infection Control, 46(1), 39-43. doi: 10.1016/j.ajic.2017.08.002

48. Hooker, E. A., Bochan, M., Reiff, T. T., Blackwell, C., Webb, K. W., \& Hart, K. W. (2015). Decreasing Clostridium difficile healthcare associated infections through use of a launderable mattress cover. American Journal of Infection Control, 43(12), 1326-1330. doi:10.1016/j.ajic.2015.07.002 